\title{
The role of entrepreneurship education on job creation among youths in Nigeria
}

\author{
Sule Maina \\ The Department of Marketing, Ramat Polytechnic, Maiduguri, Nigeria \\ E-mail address: sulemaina@yahoo.com
}

\begin{abstract}
The progress of a nation is a function of the level of the resourcefulness of the people which to a great extent, relates to the level of quality of the training and purposeful development of education in that nation. Such progress or development could only occur when an individual in the society is gainfully employed and per capital income is enhanced. This could only be possible when government educational policies are geared towards a functional education that can lead to job creation and also self reliance. Entrepreneurship education is a means through which government could attain such development in the society. Therefore, this paper examines how the role of entrepreneurship education and how it could help in job creation in Nigeria. The challenges of quality entrepreneurship education were also discussed. Finally, the paper advanced some suggestions on how to overcome the challenges so as to reduce unemployment and enhances job creation in Nigeria.
\end{abstract}

Keywords: Entrepreneurship; Entrepreneurship Education; Job Creation; Youths and Nigeria

\section{INTRODUCTION}

Education is the key to national development. This is because it unlocks the economic potentials of the people; empowers and equips individuals in society to participate in, and benefit from their national economy; facilitates economic development and provides the basis for transformation. Education is the essential tool for sustainability. The present global economic crises suggest that the entire world is in a war between financial/qualitative education and catastrophe. (Aluwong, 2010)

Entrepreneurship education as part of the total educational system is the type of education that involves the acquisition of skills, ideas and management abilities necessary for job creation. An entrepreneur promotes employment rather than seeking for an employment. Therefore, there is a need to embrace this type of education and provide all the necessary resources needed to make functional. Quality entrepreneurship education could be used as a tool for fighting the war against poverty and unemployment in Nigeria.

Education is said to be qualitative when the input such as students, teachers, finance, facilities and equipment and all these are converted through teaching and learning (theory and practical) and produce a desirable output. The output is better equipped to serve themselves and the society. The quality of input influences to a large extent the quality of output. In other words, the quality of the input of entrepreneurship education such as teachers, students and infrastructural facilities will influence greatly, the input of the output (Olorunmolu, 2010). 
Therefore, quality entrepreneurship education will enhance job creation which will subsequently reduce unemployment, poverty and social vices in Nigeria. This will also help to improve the standard of living; hence promote social economic and political development in Nigeria which is the cardinal objective of Millennium Development Goals (MDGs). Also, for the recipient of entrepreneurship education to be a job creator rather than job-seeker, he might acquire essential basic skills and attitudes which will enable him to function as an entrepreneur.

However, there are some challenges militating against the production of quality entrepreneur in Nigeria. These may come from the government, parents or even from certain unpredictable environmental forces which are external. Unless these problems are looked into, the realization of the aim and objectives of quality entrepreneurship education in achieving the Millennium Development Goals (MDGs) in Nigeria will be a mirage. It is therefore, against this background that this paper examines quality entrepreneurship education: A panacea for job creation in Nigeria.

There is now a very serious attention paid to entrepreneurship education in tertiary institutions in Nigeria and the world-over. Gibson (2001), defined entrepreneurship as the process of using private initiative to transform a business concept into a new venture or to grow and diversify an existing venture or enterprise with high great potential. The reason for this ofcourse is obvious, Nigeria educational system that turns out graduates from about 150 Universities and 50 Polytechnics and Monotechnics have not trained our graduates to be self reliant, but to depend solely on white collar jobs for sustenance. As a result, there are several graduates from Nigerian Universities today who are not gainfully employed. Apart from the book knowledge that they gained there are no requisite skills to make them self dependent. There is therefore the need to engage the youth who constitute over 60 percent of the population in meaningful engagement to avoid unhealthy alternatives for this group of people.

Henry (2003), views entrepreneurship as the engine driving the economy of nations, creating new industries, young entrepreneurs, employments and wealth. Also in the view of Agbionu (2008), entrepreneurship involves a process aimed at creating wealth for the purpose of growth, development of the environment and eradication of unemployment for national sustainability. The 2010 Global Monitoring Report (GMR) of the United Nation Education, Scientific and Cultural

Organization (UNESCO), revealed that about 92 per cent of Nigerian population survive on less than 2 dollar daily, while about 71 per cent survives on less than 1 dollar daily - a condition many have described as inexcusable judging from the abundant natural deposits and high human population at the country's disposal. With an estimated population of about 167 million people (2011) and crude oil selling as high as \$104 dollar per barrel in the global market as at July 2012, the high level of poverty in comparison to the abundant resources available in Nigeria is highly unacceptable. There is therefore the urgent need for government and individuals to create more job opportunities for the teaming youths.

It is believed that employment of Nigerian graduates either part-time, full-time or even under-employment can be said to have eluded Nigerian youths with Nigeria said to have one of the highest rates of youth unemployment in the unindustrialized world. Despite strong economic growth, youth's full-time unemployment rate for 2006-2008 in Nigeria was put at $55.9 \%$ while countries like Japan, China, India, Korea, have joined community of industrialized nations by strengthening their small scale industries. Nigeria is yet to understand the relevance of this sub-sector. 


\section{THE CONCEPT OF ENTREPRENEURSHIP}

Entrepreneurship is the purposeful activity (including an integrated sequence of decisions) of an individual or group of associated individuals, under-taken to initiate, maintain, or aggrandize a profit-oriented business unit for the production or distribution of economic goods and services (Nwachukwu, 1990). Entrepreneurship at least in all non-authoritarian societies constitute a bridge between society as a whole, especially the non-economic aspect of that society, and the profit oriented institutions established to take off its economic development and to satisfy, as best they can, its economic desires.

Schumpeter (1994) defines entrepreneurship as the ability to perceive and undertake business opportunities, taking advantage of scarce resource utilisation. In simplest form, entrepreneurship is the willingness and the ability to seek out investment opportunities and to run an enterprise for profit. In this later sense, entrepreneurship takes premium over capital. It is equally more fundamental than capital because capital formation is the result of entrepreneurial activity. Entrepreneurs are therefore regarded as central figures in economic development. Their contributions run through labour actions, movement of capital goods and conversion of raw materials into finished products, and ultimately, effectual distribution of the products to final consumers. Entrepreneurs are therefore those who search and discover economic opportunities, marshal the financial and other resources necessary for the development of the opportunities, evaluate alternatives available in the environment and allocate resources to the most profitable ones and as well take the ultimate responsibility for the management and/or successful execution of opportunities. An Entrepreneur is somewhat comfortable with taking and assuming risks which are impassioned with the dream being pursued. He or she knows where to get help, and when it is needed, and as well as being ever ready to receive changes in the business surrounding environment (Schumpeter, 1994). Consequently, universities should commence training high level manpower whose characteristics are usually obsessive, focused, articulate, and resourceful. In this way graduates will turn out typically charismatic leaders, and tend to be introspective in the skills of job creation, wealth generation and innovative skill utilization.

Empowering the Nigerian people towards wealth creation, employment generation, poverty reduction and value re-orientation (NEEDS, 2005), is a foremost cardinal point for strategic macro-economic framework. This also reflects in the recent increase in the demand for educational programmes in entrepreneurship in the country's tertiary institutions, parastatals and non-governmental paradigms. If fully satisfied, this new vision and values would shine the spotlight on small medium scale business activities in Nigeria. Thus, increased education on entrepreneurial skills would create that perfect opportunity to stimulate economic growth. Institutions are therefore to properly train individuals who will have the right tools necessary to commence and grow successful businesses with reduced risk of failure.

Entrepreneurship is frequently a scarce resource because entrepreneurs are gap fillers and inputs completers and these are highly scarce talents. David C. McClelland of Harvard University, U.S.A., highlighted this paramount importance of entrepreneurship in his "Need Theory of Entrepreneurship". McClelland made a comprehensive contribution to the conceptualization of motivators to entrepreneurship development by identifying three types of basic motivating needs which he classified as need for power (n/PWR), and need for affiliation (n/AAF), and need for achievement (n/ACH).

Considerable research has been done on method of testing people with respect to these three types of needs, and McClelland and his associates have done substantial research, especially on the need for achievement drive. Research on achievement needs has been 
noteworthy and is often used by psychologists as a prototype of how knowledge should be researched and discovered in the behavioural science as a way of developing entrepreneurship. All three drives; power, affiliation and achievement, are of relevance to management since all must be recognised to make organised enterprise work well, because such enterprise and its departments represents group of individuals working together to achieve goals, hence the paramount importance of the need for achievement in entrepreneurship development.

\section{1. Need for Power}

McClelland and his associates postulated that people with a high need for power have a greater concern for exercising influence and control. Such individuals, and/or societies generally seek positions of leadership, they are forceful, outspoken and they enjoy teaching others as well as form a public mouth-piece. According to NEEDS (2005), Nigeria as a nation with high need for power is a founding member of the New Economic Partnership for African Development and the Economic Community of West Africa (ECOWAS). This also explains why 92 percent trainee teachers in Technology education at the University of Lagos indicated willingness to interact with industries while the studentship lasted (ILO, 1995).

\section{1. Need for Affiliation}

People with a high need for affiliation are noted to always desire pleasure from being loved and as such tend to avoid the pain of being rejected by a social group. As individuals, they are likely to be concerned with maintaining pleasant social relationships to enjoy a sense of intimacy and understanding, to be ready to console and help others in trouble, and to enjoy friendly interaction with others.

\subsection{Need for Achievement}

Also, people with a high need for achievement are noted to have intense desire for success and equally intense fear of failure. They want to be challenged, they set moderately difficult (but not impossible) goals for themselves, take a realistic approach to risk (they are not likely to be coin tossers, but rather to analyze and assess problems), prefer to assume personal responsibility to get a job done, like specific and prompt feedback on how they are doing, tend to be restless, like to work long hours, do not worry unduly of failure if it does occur, and tend to like to run their own shows. People with this type of behaviour were confirmed to often become entrepreneurs.

Besides, McClelland and his associates emphasized that apart from the reason of market structure and other input deficiencies, entrepreneurial activities as well as entrepreneurs also arise because of the need to develop new skills, ideas and products; the need to provide leadership, motivation, direction and an organization so as to solve potential crisis situations, and the capacity to carry ultimate responsibilities for the organizational structure, and the need to provide time-binding contractual arrangements. They concluded by enumerating some factors that could promote entrepreneurship development. These are as follows:

i. A free and democratic society,

ii. A free enterprise economic system,

iii. The rate of growth of the economy (the greater the rate of growth, the higher the challenge for entrepreneurship development),

iv. The opportunity costs of developing private initiative, 
v. The available alternatives in the environment,

vi. The behaviour of entrepreneurs in choice and decision making (the need to achieve),

vii. The rewards system in the society (the higher the reward system, the greater the challenge to be an entrepreneurs),

viii. The attitude of the society (interest in sharing and releasing their assets for productive and profitable activities),

ix. The tradition and culture of the people, cultural beliefs and taboos,

$\mathrm{x}$. The motivational tools and techniques available to the entrepreneur, that is, technology in use,

xi. The educational system in the society,

xii. The motive of an individual (whether risk averter or risk taker can develop into entrepreneurs),

xiii. Political reformation, religious tolerance, security, adequate and appropriate amenities, e.t.c.

xiv. The possession of an achievers behaviour and attitude, and

xv. Poverty, inability to raise fund and/or obtain loan easily.

Besides, the traditional definition of development by economists which emphasized longterm sustained increase in national income per head, has given way to new concepts and definitions involving desirable changes in social structures, institutions, attitudes, income distribution, freedom of choice, quality of life and capabilities, in addition to sustained appreciable growth in national income. The definition of Todaro and Smith (2003) properly pictures the new concept about development thus:

"Development, in its essence, must represent the whole gamut of change by which an entire social system, added, to the diverse basic needs and desires of individuals and social groups within that system, moves away from a condition of life widely perceived as unsatisfactory toward a situation or condition of life regarded as materially and spiritually better".

Todaro and Smith did not only agree that the concept of development is a multidimensional process that goes beyond economic growth, but also have reviewed other literature on the term "development" and came up with three core values of development as well as three objectives of development as a practical and universal basic for the concept of development.. In this same line of reasoning, developing countries including Nigeria have put forward more practical and encompassing objectives of development. For example, from a synthesis of Nigeria's national development plans of the 60s, 70s and early 80s, Fashola (2006) notes that the following objectives may be a summary of the entire development plans of this country since 1960 to hitherto. They are:

i. Appreciable growth in national income that will raise per capita income significantly,

ii. Promotion of self-reliant economic development (particularly in regard to balance of payments solvency and technological self-reliance),

iii. Promotion of equitable income distribution and social justice,

iv. Promotion of price stability,

v. Promotion of fuller employment,

vi. Balanced socio-economic development, and

vii. Protection of the physical environment and ecological balance.

A critical scrutiny of the above development objectives reflects in no little measure the essence and need for the development and expansion of our entrepreneurial sector, the role of 
which is very significant here in expediting the successful attainment of the aforementioned objectives.

\section{4. The Concept of Entrepreneurship Education}

Entrepreneurship education and training becomes very important machinery to meet this national goal. Nevertheless, while it is not absolutely necessary for an individual to obtain entrepreneurship training to be successful, obtaining an entrepreneurial education serves as a tremendous advantage to increasing the chances of success as an entrepreneur. This is because training is still focused and directed at achieving a purpose while education is all encompassing. Thus, great strides are required to be made towards the goal of educating people to become entrepreneurs to enhance economic growth and development.

\section{5. Objectives of Entrepreneurship Education}

The objectives of entrepreneurship education clearly show that it is concerned with the development and survival of both the individual and society. In fact, it is a tool through which social, economic and political development could be achieved. If it is properly planned, funded and implemented. The objectives of entrepreneurship education are spelt out by Osuala (2010) as

1. To provide meaningful education for youth which could make them self-reliance and subsequently encourage them to drive profit and be self independent

2. To provide graduate with the training and support necessary to help them establish a career in small and medium size business.

3. To provide graduates with training skills that will make them meet the manpower needs of the society.

4. To provide graduates with enough training in risk management to make uncertainty bearing possible and easy.

5. To stimulate industrial and economic growth of rural and less developed area.

6. To provide graduate enough training leer will make them creative and innovative in identifying new business opportunities.

7. To provide small and medium sized companies with the opportunity to recruit qualified graduates who will receive training and tutoring in the skills relevant to management of the business centre.

From the above objectives, it is evident that this type of education if it is given all it deserves and properly implemented will produce quality graduates that will foster job creation and reduce or eliminate poverty in Nigeria. This could be realized when the graduates are selfreliant by establishing their own business small/medium scale enterprises.

Job creation is one of the cardinal objectives of Millennium Development Goals. When an ample job opportunities is created it will invariably help to reduce poverty and enhance better standard of living of an individual in Nigeria. Job creation is an act of making work in which one receive regular payment available to the citizenry. That is creating an enabling environment for ample employment opportunities in the society. This is done by establishing cottage, small/medium scale enterprises in Nigeria. 


\section{6. The Concept of Youth Unemployment}

Unemployment and poverty were strange to the country before the 1980's. It was therefore not a headache to the nation as to how to solve these problems. But after the 1980's, the need for entrepreneurship education started to rear its head because of political instability and also because of the inconsistencies in the social-economic policies of successive governments which in part led to the unabating unemployment situation in the country today. In the mid 80's the Nigerian economy collapsed while youth and graduate unemployment in Nigeria hit the roof. Workers were laid off and early retirement was the in-thing as a result of Structural Adjustment Programme and bad economic trends in the country. It was then observed that the philosopher of self-reliance such as creating a new cultural and productive environment that will promote pride in primitive work and selfdiscipline was lacking in tertiary institutions. Nwagwu (2007) opined that the failure of tertiary education to inculcate the above philosophy in students has led to the wastages in both human and natural resources. This is because the youth and the graduates from tertiary institutions are not equipped with the skills with which to exploit the natural resources that abound in Nigeria.

\section{7. How Entrepreneurship Education Could Help in Job Creation}

Quality Entrepreneurship Education plays a vital role in the social, political and economic development of any Nation. This is possible when jobs are created for the citizenry by establishing a lot of businesses that will accommodate the unemployed youth in Nigeria. A qualified graduate of entrepreneurship education would have acquired enough skills relevant to management of small business centre.

- Creation of self-employment. An entrepreneur provides job for himself by establishing small business centre. This, according to Aiyeduso in Olorunmolu (2008) helps to reduce the problem of unemployment and other social vices in Nigeria. The entrepreneur does not only provide jobs/employment for himself alone, but provides for others too. This in turn helps the individual to increase per capital income hence improve standard living.

- The Entrepreneur determines or identifies the specific wants of the people and the type of goods and services that will fulfill those wants most comfortable. Emeruwa (2005) asserted that the entrepreneur does not only identifies but mobilizes and organizes the resources to tap the opportunities by assisting men, materials, money and machines to explore the opportunity.

- Production of goods and services that is important to the well-being, comfort and happiness of individuals in the society at large.

- Entrepreneurship stimulates rural, economic and industrial development. They contribute to the development of rural areas. They do this by establishing their small/medium scale enterprise in such areas by discouraging rural migration.

They provide ample job opportunities to the rural dwellers. They also provide goods and services, which could be found in an urban area and sometimes provide infrastructural facilities. - The entrepreneurs are usually motivated in their activities not only by the need for material contributions to the welfare of the communities but also desire to make profit. This uplifts the dignity of labour.

- Through entrepreneurship education, utilization of local resources is made possible. The graduates of this specialized education set up their small/medium scale business, which will enable them to utilize the local resources available in their vicinity. The uses of local raw materials are discarded by products of large firms as primary input in their production processes. Owualah in Olorunmolu (2008) asserted that in terms of their economic benefits 
small firms can be said to be greater in local resources maximizes than their large counterparts. The provision of raw materials for the big firms help them to increase their production hence employ more personnel thereby creating jobs for unemployed youth in the country.

- Through entrepreneurship education, A pool of potential entrepreneurs who are well equipped with skills and technical know how to manage small/medium scale industries are produced. This will equally help in job creation. Through quality entrepreneurship education, Nigeria could produce a lot of entrepreneurs who could establish and manage businesses on their own. Based on the above merits, it is no doubt that entrepreneurship education could be used as major weapon in achieving the Millennium Development Goals (MDGs) by empowering the individual in the society to be self- reliant. This will help reducing poverty in Nigeria.

\section{8. Challenges of Entrepreneurship Education in Nigeria}

Quality Entrepreneurship Education could played a vital role in equipping individual with necessary intellectual capacity, skills and right type of work habit and attitude to be able to create jobs for the growth of the Nigeria economy. However, what is quite essential is the extent to which the entrepreneurship Education programme can be implemented to realize these goals. The programme is confronted with a lot of challenges which brought a setback in the attainment of its objectives. These challenges have not enable Nigerian to enjoy the benefits of this programme as expected. This limits the achievement of the millennium development goals (MDGs) in Nigeria.

Some of the challenges have been pointed out by eminent scholars such as Gana (2000), Aiyeduso (2004), Osuala (2010) and they include:

- Poor funding by government and Non-governmental organizations.

- Poor or ineffective planning, supervision information and evaluation of the programme across the board.

- Inadequate teaching materials, equipment and infrastructural facilities.

- The challenges posed on globalization, information and communication technology (ICT) have effect on curriculum, methodology, facilities, staff and equipment.

- Inadequate qualified teachers and instructors as well as supporting staff at all level.

- Inadequate motivation for available teaching and non teaching staff which affects staff efficiency, retention, creativity and initiative.

- Emphasis on theoretical Knowledge rather than practical knowledge due to lack of entrepreneurship education centre.

- High level of corruption and very poor maintenance culture in the system.

- Poor enabling business environment, access to credit/ loan, infrastructural decay, mass poverty, inflation, technological infraction, political instability and insecurity of lives and properties which hamper economic and business activities.

\section{CONCLUSION / RECOMMENDATION}

Since early 1980's, Nigeria has a history of economic stagnation that has led to decline in white collar jobs. The inclusion of entrepreneurship course in all disciplines will to a great extent, assist in solving this problems of high unemployment and underemployment. Entrepreneurship education in this paper has been recognized as a key driver in encouraging business start up potentials among graduates (Wilson, Llewellyn and Robertson 2003:9) cited in Mafela (2009:3). 
Some argue that entrepreneurial capabilities are not inborn and as such entrepreneurship is a behavioural not a personality trait but can be learned. All the same, the attempts at stimulating entrepreneurial activities through formal training and education and therefore assume that they may be enhanced or developed by a guided entrepreneurial education. Others believe that entrepreneurship is inborn, that is, personality trait not behavioural. There are yet others including this author who believe that entrepreneurship is primarily learned by experience and discovery and that entrepreneurial learning should be conceived as a lifelong process, where knowledge is continuously shaped and revised as new experience take place. It is against this background that the following recommendations are proffered for effective entrepreneurship education in Nigeria.

1. All stakeholders must encourage the proposed introduction of Entrepreneurship study across faculties and departments as general courses in the country. The federal government in collaboration with state governments should provide scholarships/bursaries for performing students by way of encouragement.

2. Universities should start to commercialize their research findings instead of leaving them in the shelves.

3. The National Universities Commission (NUC) should as usual set the minimum benchmark of the courses in Nigerian universities. This development should not be politicized, rather, the entire policy frameworks needed for its sustainability and improvement should be provided so as to salvage Nigeria from the clutches of poverty.

\section{Reference}

[1] Agbionu T. U. The Basics of Business Success: An Entrepreneurship Practical Approach. Lagos: Topline Publishers.

[2] Aiyeduso A. O. (2004). Principles and methods of business and computer education. Enugu, Cheston Agency Ltd Pub.

[3] Akeredolu-Ale E. O. (1975). The Underdevelopment of Indigenous Entrepreneurs in Nigeria. Ibadan: University Press.

[4] Aluwong S. W. (2010). Entrepreneurship and functional business education as a means of achieving the national objectives of vision 2020 in Nigeria. Organized by National Association for Research Development held at Nasarawa State University, Keffi. (13th17th Sept, 2010).

[5] Emeruwa C. O (2005). Capacity building entrepreneurial development. Paper presented at FCE (T) Potiskum on ETF Capacity Building held on 13th-25th.

[6] Fashola M. A. (2006). "The Concept and definition of Development", \& Paper Presented to the School of Post-Graduate Studies Department of economics, University of Lagos, Akoka, Lagos.

[7] Gana J. S. (2001). Entrepreneurship, Kaduna: Jofegan Associates.

[8] Gana J. S. S. (2000). Entrepreneurship. Jos, Jofegan Associate Pub.

[9] Gibson A. (1997). Business Development Services - Core Principles and Future Challenges. London: Small Enterprises Development. 
[10] Henry F. I. (2003). Entrepreneurship Development in Third World. A Realistic Approach. New York: Graw Hill Inc.

[11] Hornby A. S. (2000). Oxford advanced learner's dictionary. United Kingdom: Oxford University Press.

[12] Joseph O. O., Esther A. A. (2012). Quality Entrepreneurship Education: A Panacea for Job Creation in Nigeria, Journal of Resourcefulness and Distinction, Volume 1, No. 1, April, 2012

[13] Nigeria (2004). National Policy on Education (Revised Edition) NERDC.

[14] Nwachukwu L. C., Nwamuo P. (2010). Entrepreneurship Development for Sustainable Livelihood among Youths in Imo State: Implications for Counselling, Conference Proceedings, CASSON.

[15] Nwagwu Ig. O. (2007). Higher Education for Self-Reliance: An Imperative for the Nigerian Economy. NEAP Publication.

[16] National Planning Commission (2005). National Economic Empowerment and Development Strategy (NEEDS). Reprinted by CBN.

[17] Olorunmolu J. O., Sahel Journal of Teacher Education 1(1) (2008) 33-39.

[18] Olorunmolu J. O., Journal of management science and Technology Education 4(1) (2010) 110-115.

[19] Ojeifo S. A. (2013). Entrepreneurship Education In Nigeria: A Panacea For Youth Unemployment, Journal of Education and Practice www.iiste.org ISSN 2222-1735 (Paper), ISSN 2222-288X (Online) Vol. 4, No. 6, 2013,

[20] Osuala E. C. (2010). Principles and methods of business and computer education. Enugu: Cheston Agency Ltd Pub.

[21] Nwachukwu C. C. (1990). The Practice of Entrepreneurship in Nigeria. Onitsha: African Fep. Publishers.

[22] Schumpeter P. (1994). Tough Times Never Last. But Tough People Do, U.S.A.: Thomas Nelson Inc.

[23] Todaro M. P., Stephen C. Smith (2003). Economic Development, 8th edition, New York: Pearson Education.

[23] UNDP (1992). Human development Report, New York: Oxford University Press. 